\title{
Topic- Hemophagocytic Lymphohistiocytosis: A New Foe
}

\author{
Rohit Vohra ${ }^{1 *}$ and Dr Minakshi ${ }^{2}$ \\ ${ }^{1}$ Department of Pediatric emergency and critical care medicine, Sir Ganga Ram Hospital, India \\ ${ }^{2}$ Department of Pediatric Hematology and Oncology, Sir Ganga Ram Hospital, India
}

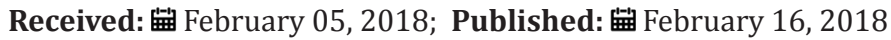

*Corresponding author: Rohit Vohra, Department of Pediatric emergency and critical care medicine, Sir Ganga Ram Hospital, New Delhi, India

\begin{abstract}
Hemophagocytic lymphohistiocytosis (HLH) is an aggressive and life-threatening syndrome of excessive immune activation. It commonly affects infants from birth to 18 months of age, but the disease can be seen in children and adults of all ages. HLH can occur as a familial or sporadic disorder, and it can be triggered by a variety of events that disrupt immune homeostasis. Prompt recognition of the disease and initiation of treatment is essential for the survival of affected patients [1].
\end{abstract}

Keywords: HLH; NK cells; Immune system

Abbreviations: HLH: Hemophagocytic lymphohistiocytosis; NK: Natural killer; CTLs: cytotoxic T- lymphocytes

\section{Introduction}

HLH is an aggressive and life threatening syndrome of excessive immune activation.HLH is not a single disease entity but rather a syndrome consisting of clinical signs and laboratory abnormalities that result from the uncontrolled proliferation and activation of cells of the monocyte/macrophage lineage. It is characterized by highly activated lymphocytes and macrophages that infiltrate tissues and produce large amounts of proinflammatory cytokines $[1,2]$. The term hemophagocytosis describes the pathologic finding of activated macrophages, engulfing erythrocytes, leukocytes, platelets, and their precursor cells; typically seen in bone marrow, spleen and lymph nodes. It can rarely be seen in central nervous system, skin and peripheral blood. This phenomenon is an important finding in patients with HLH. However, it may be absent in initial stages of the disease [3]. PATHOPHYSIOLOGY-Macrophages are antigen presenting cells derived from circulating monocytes; they present foreign antigens to lymphocytes. In HLH, macrophages become activated and secrete excessive amounts of cytokines. This leads to severe tissue damage that can result in organ failure. In HLH, Natural killer (NK) cells and cytotoxic T- lymphocytes (CTLs) fail to eliminate activated macrophages. This results in excessive macrophage activity and highly elevated levels of interferon gamma plus other cytokines. Most patients with HLH also exhibit impaired cytotoxic function of NK cells and CTLs [4].
In addition to increased cytokine production, macrophages can also phagocytize host cells. Hemophagocytosis refers to the engulfment of host blood cells by macrophages. Hemophagocytosis is characterized by the presence of red blood cells, platelets, or white blood cells (or fragments of these cells) within the cytoplasm of macrophages. It can be seen on biopsies of immune tissues (lymph nodes, spleen, liver) or bone marrow aspirates. Hemophagocytosis alone is neither pathognomonic of, nor required for, an HLH diagnosis. CLASSIFICATION-HLH can either be genetic, inherited in an autosomal recessive pattern or it can be acquired due to trigger of various infections, malignancies or rheumatic diseases (MAS). Familial HLH is then further sub-classified as with and without hypopigmentation [5].

\section{Familial HLH}

a) Familial HLH without Hypopigmentation: FHL 1, FHL 2, FHL3, FHL4, FHL5

b) Familial HLH with Hypopigmentation: Gricelle syndrome, HermanskyPudlaksyndrome, Chediak Higashi syndrome

\section{Lymphoproliferative Disorder}

X- linked lymphoproliferative disorder- 1 (XLP-1), XLP2, Interleukin -2 Inducible T- cell Kinase (ITK) deficiency, CD 27 
deficiency, X - linked immunodeficiency with magnesium defect (XMEN) syndrome

\section{Macrophage Activation Syndrome}

\section{c) Acquired HLH}

\section{Diagnosis}

Revised Diagnostic Guidelines for HLH- 2004 [6].

A. A molecular diagnosis consistent with HLH (mutations of PRF1, UNC13D, STX11 or STXBP2 are identified) OR

B. Fulfillment of five out of the eight criteria listed below:

a) Fever

b) Splenomegaly

c) Cytopenias (affecting at least two of three lineages in the peripheral blood)

i. Hemoglobin $<9 \mathrm{~g} / 100 \mathrm{ml}$ (in infants $<4 \mathrm{wk}$ : hemoglobin $<10 \mathrm{~g} / 100 \mathrm{ml}$ ).

ii. Platelets $<100 \times 10^{3} / \mathrm{ml}$. iii. Neutrophils $<1 \times 10^{3} / \mathrm{ml}$.

d) Hypertriglyceridemia (fasting, $\geq 265 \mathrm{mg} / \mathrm{dl}$ ) and/or hypofibrinogenemia $(\leq 150 \mathrm{mg} / 100 \mathrm{ml})$

e) Hemophagocytosis in bone marrow (BM), spleen or lymph nodes

f) Low or absent NK cell activity

g) Ferritin $\geq 500 \mathrm{ng} / \mathrm{ml}$

h) Soluble CD25 (that is, soluble IL-2 receptor) $>2400 \mathrm{U} / \mathrm{ml}$ (or per local reference laboratory)

\section{Treatment}

HLH is a progressive syndrome of unchecked immune activation and tissue damage. If left untreated, patients with HLH survive for only a few months, due to progressive multi-organ failure. Currently there are two protocols given by Histiocyte Society HLH94 and HLH 2004 used in treatment of HLH. Both have some minor differences but latest results shows that both are equally efficacies in treatment of HLH [7] (Figures $1 \& 2$ ).

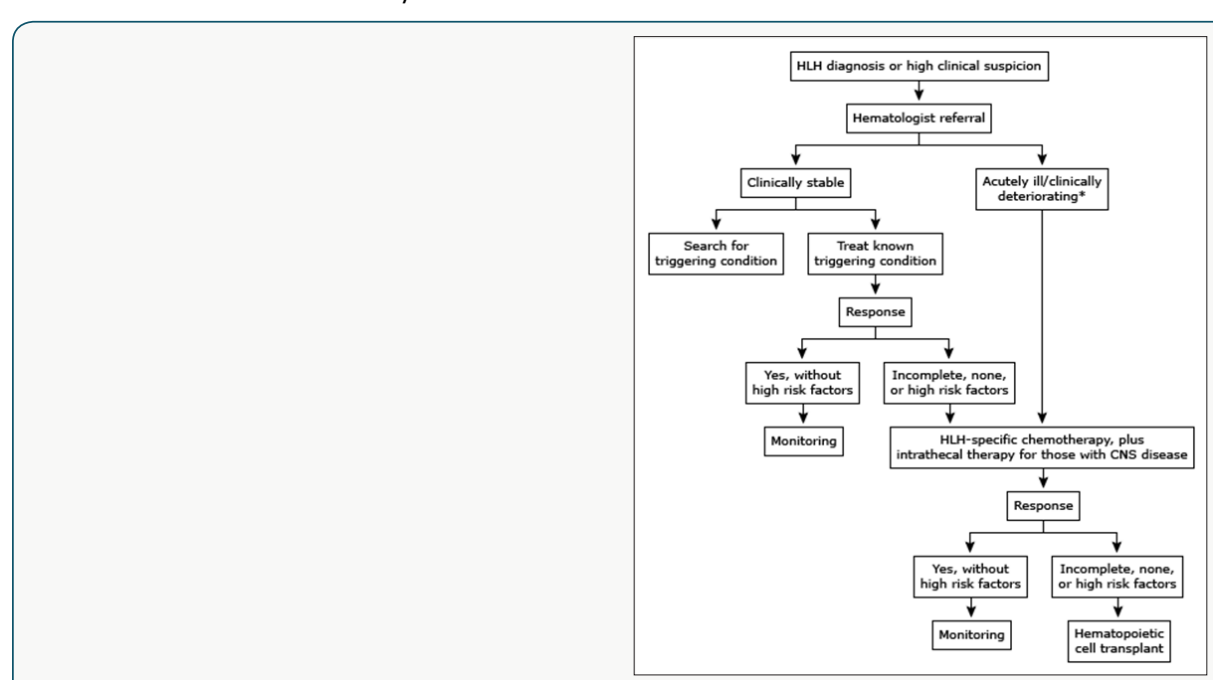

Figure 1:

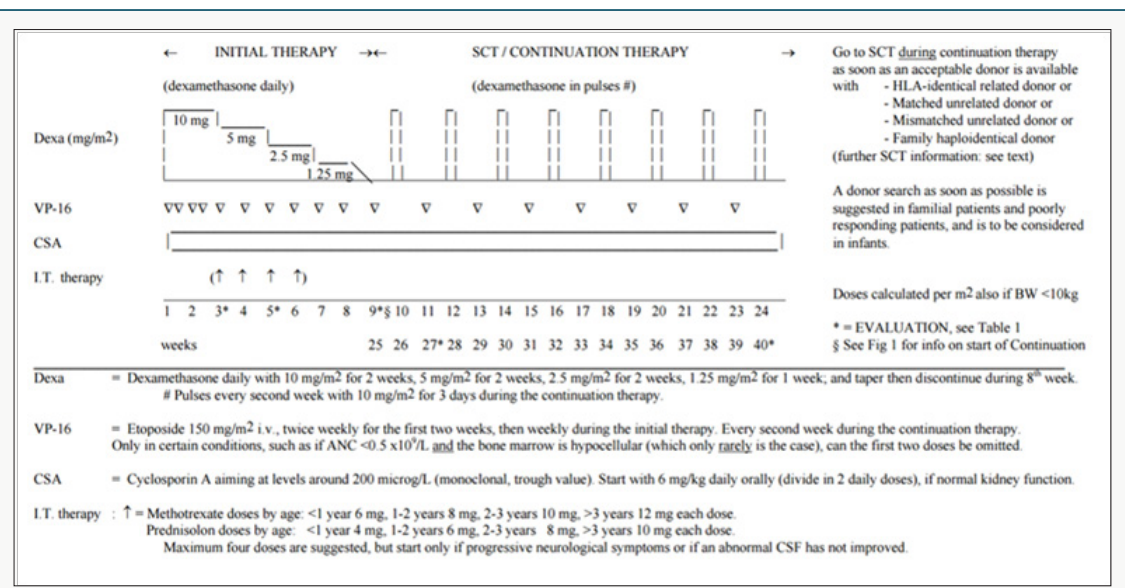

Figure 2: Treatment protocol overview for Hemophagocytic Lymfohistiocytosis (HLH-2004) 


\section{References}

1. McClain K (2017) Clinical features and diagnosis of hemophagocytic lymphohistiocytosis.

2. Madkaikar M, Shabrish S, Desai M (2006) Current Updates on Classification, Diagnosis and Treatment of Hemophagocytic Lymphohistiocytosis (HLH). Indian J Pediatr 83: 434-443

3. George, Melissa R (2014) Hemophagocytic Lymphohistiocytosis: Review of Etiologies and Management. Journal of Blood Medicine 5: 69-86

4. Risma K, Jordan MB (2012) Hemophagocytic lymphohistiocytosis: updates and evolving concepts. Curr Opin Pediatr 24(1): 9-15.
5. George MR (2014) Hemophagocytic lymphohistiocytosis: review of etiologies and management. J Blood Med 5: 69-86.

6. Henter JI, Horne A, Arico M (2007) HLH-2004: diagnostic and therapeutic guidelines for hemophagocytic lymphohistiocytosis. Pediatr Blood Cancer 48(2): 124-131.

7. Elisabet Bergsten, AnnaCarin Horne, Maurizio Aricó, ItziarAstigarraga, R. Maarten Egeler, et al. (2017) Confirmed efficacy of etoposide and dexamethasone in HLH treatment: Long term results of the cooperative HLH-2004 study. Blood 130(25): 2728-2738.

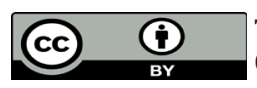

This work is licensed under Creative Commons Attribution 4.0 License

To Submit Your Article Click Here:

Submit Article

DOI: $10.32474 /$ PAPN.2018.01.000108

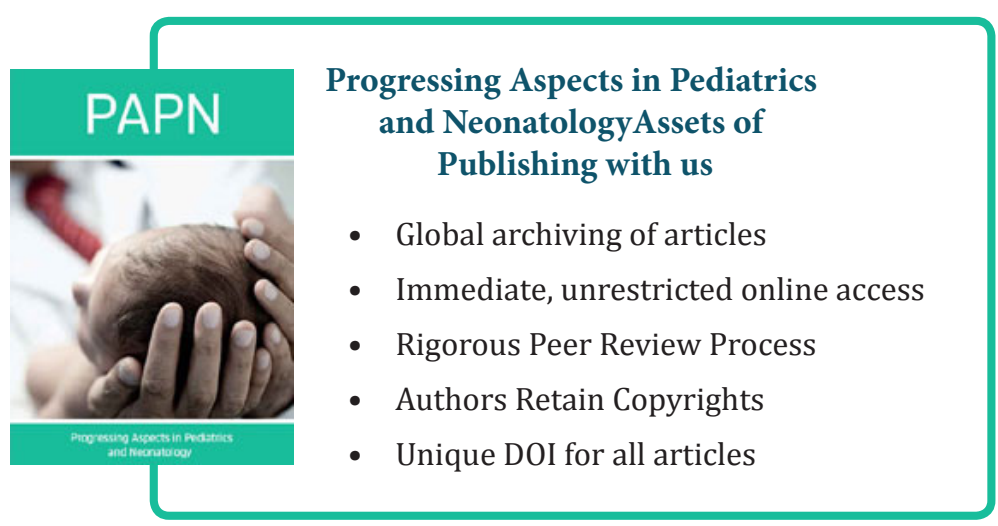

